\title{
Observação sobre a presença de Columba livia doméstica em uma praça no município de Ituiutaba-MG
}

\author{
Flávio Caldeira Silva \\ Instituto Federal do Triângulo Mineiro - Campus Ituiutaba (IFTM) \\ (flaviocaldeira@iftm.edu.br) \\ Michelle Stafy Franco Souza \\ Instituto Federal do Triângulo Mineiro - Campus Ituiutaba (IFTM) \\ (michellestafy@yahoo.com.br) \\ Ubiramar Ribeiro Cavalcante \\ Universidade do Estado de Minas Gerais (UEMG) \\ (ubiramarrc@gmail.com)
}

\begin{abstract}
Resumo: Em todo o Brasil o Columba livia, conhecido como pombo doméstico ou pombo urbano é encontrado com grande facilidade, seja nos grandes ou médios centros urbanos, eles estão convivendo juntos com a população, e estão bem adaptados à cidade. Estas aves têm sido consideradas vetores de agentes infecciosos de importância em saúde pública, sendo que do ponto de vista epidemiológico, os pombos têm um papel importante na contaminação do meio ambiente e na dispersão de patógenos através da deposição de suas excretas (SILVA \& CAPUANO, 2008). O trabalho foi realizado em uma praça no município de Ituiutaba-MG. Este estudo teve como objetivo observar a presença de pombos e o comportamento dos mesmos perante a dinâmica da praça Cônego Ângelo Tardio Bruno, no município de Ituiutaba, MG, enfatizando o risco de infecção humana e a animais. As observações foram realizadas no período da manhã entre as 07:00 às 11:00h e no período da tarde das 13:00 às 17:30h. Cada visita, no local, teve uma duração média de quatro horas. As atividades de observação e avaliação tiveram início em fevereiro de 2016, totalizando 09 dias. Para as avaliações das presenças das espécies e da dinâmica da praça e seu entorno foram realizados registros fotográficos e observações visuais. Constatou-se que no período da manhã e da tarde há a presença das aves, e as fezes das mesmas em vários locais da praça, que é um local com grande fluxo de pessoas. Foi verificado também que na praça existe a presença do Projeto Cão de Rua, que são recipientes com alimentos e água para cães que vivem nas ruas, atraindo os pombos para aquele local, contaminando os alimentos e a água com suas fezes, podendo desta forma transmitir doenças para os cães.
\end{abstract}

Palavras-chave: pombo doméstico; fezes; doenças.

\section{Observation on the presence of domestic Columba livia on a square in the municipality of Ituiutaba-MG}

\begin{abstract}
Throughout Brazil the Columba Livia, known as the domestic pigeon or urban pigeon, is found abundantly, whether in large or medium urban centers. They live among the population, and are well adapted to the city. These birds have been considered vectors of infectious agents of public health importance, and from the epidemiological point of view, pigeons play an important role in the contamination of the environment and the dispersion of pathogens through the deposition of their excreta (SILVA \& CAPUANO, 2008). The work was carried out on a square in the municipality of Ituiutaba-MG. The aim of this study was to observe the presence of pigeons and their behavior in Ituiutaba, MG, emphasizing the risk of human and animal infection. Observations were made in the morning between 07:00 and 11:00 and in the afternoon from 1:00 to 5;30 pm. Each visit, on the spot, lasted on average of four hours. Observation and evaluation activities began in February 2016, totaling 9 days. To evaluate the species presences and the dynamics of the square and its surroundings, photographic records and visual observations were made. It was analyzed that during the morning and the afternoon the presence of these birds increase, as well as their feces around the place, being among the people. It was also verified that on the square there is the presence of the Dog Street Project, which are containers with food and water for dogs that live on the streets, attracting the pigeons to that place where they contaminate food and water with their feces, this way passing on diseases to those stray dogs.
\end{abstract}

Key-words: Domestic pigeon; Feces; Diseases. 


\section{INTRODUÇÃO}

O pombo doméstico ou pombo urbano, pertence ao filo Chordata, classe Aves, ordem Columbiformes, família Columbidae, nome científico Columba livia. É uma ave exótica, que se originou da pomba das rochas, de origem europeia, tendo sido introduzidas no Brasil no século XVI, pelos imigrantes europeus e acabou se tornando uma "praga" nas cidades.

Em todo o Brasil os pombos são encontrados com grande facilidade, seja nos grandes ou médios centros urbanos, eles estão convivendo juntos com a população, e são bem adaptados à cidade. Segundo Beck (2003), os pombos são granívoros na natureza, se alimentam de sementes, mas nas áreas alteradas pela ação do homem, eles possuem mais recursos para sua alimentação. Nas cidades, os pombos se adaptaram a alimentar-se de restos de alimentos jogados pela população. Nas residências e em locais públicos, principalmente praças, isto ocorre com maior frequência, o que não é diferente no município de Ituiutaba (local de estudo desta pesquisa). Nas praças existem uma grande circulação de pessoas, muitas das quais realizam sua alimentação nestes locais, e que deixam restos de alimentos caírem ou jogam o restante ao chão, ou nas lixeiras presentes nestes locais, e ou mesmo alimentam os pássaros por puro prazer de estar em contato direto com o meio ambiente. Os pombos se habituaram a entrar nas lixeiras para procurar e se alimentar de algum resto de comida que esteja por ali, principalmente em ambientes públicos que possuem praças de alimentação, estimular estas ações ou simplesmente não as coibir pode trazer sérios problemas, pois os pombos podem atuar como vetores de doenças e as transmitir ao homem.

O homem pode se infectar pela via respiratória, aspirando poeira de locais contaminados por fezes secas ou pela ingestão de poeira e/ou alimentos contaminados com as excretas destas aves (SILVA \& CAPUANO, 2008). Segundo Stipp, Silva, Beartchi (2011), as fezes dos pombos são ácidas, podendo causar malefícios à pintura de veículos e ao patrimônio artístico e histórico, matando plantas ornamentais e gramados, além de trazer muita sujeira, e o acúmulo de penas, fezes e restos de ninhos pode causar entupimentos em calhas ou tubulações de escoamento pluvial e o apodrecimento precoce de forros de madeira.

Além desses malefícios, as fezes podem causar problemas tanto para o homem quanto para os animais, principalmente os cães e gatos, pois se estiver fezes na água 
Observação sobre a presença de Columba livia doméstica em uma praça no município de Ituiutaba-MG

desses animais poderá transmitir doenças a eles, as principais zoonoses transmissíveis pelos pombos são: salmonelose, ornitose, criptococose, histoplasmose, dermatites e alergias.

Segundo Beck (2003), o agente etiológico causador da salmonelose é a bactéria Salmonella sp. A pessoa acometida pode ocorrer vômitos, diarreia, febre e dores abdominais. O modo de transmissão se dá pela ingestão de alimentos contaminados com fezes de pombos contendo o agente etiológico.

De acordo com a publicação feita pela Prefeitura do Município de São Paulo (2016) o agente etiológico da ornitose é a Chlamydia psittaci, pode causar doença pulmonar, vômito e diarréia ou não apresentar sintomas. A transmissão ocorre ao aspirar o pó das fezes secas dos pombos.

Segundo (BECK, 2003),

A criptococose é uma doença, classificada como micose sistêmica, o
agente etiológico é o fungo Criptoccus neofarms, que causa reações
inflamatórias mínimas, eminentemente purulenta ou granulomatosa,
com produção de nódulos ou nodos formados por macrófagos. O
fungo após instalado no homem pode localizar-se em qualquer órgão
ou tecido. Quando se aloja no pulmão produz lesões pulmonares,
podendo ser confundida com tuberculose pode levar a disseminação
da doença ao sistema nervoso central, causando a meningoencefalite.
A reação granulomatosa pode ser conspícua, formando-se nodos
tumoriformes volumosos nos rins, supra-renais, próstata, fígado
demonstrando poucos sintomas localizados. Na pele podem aparecer
lesões, tais como úlceras e tumores subcutâneos. A contaminação se
dá pela inalação dos fungos contidos nas fezes dos pombos
contaminados. Apesar de Criptoccus neoformans ser encontrado com
grande frequência no ambiente.

A criptococose meníngea é a infecção fúngica mais comum no SNC, sendo também considerada a terceira principal complicação neurológica em pacientes HIV positivo (PINTO, 2010).

Os pacientes portadores de AIDS representam a maioria dos casos de criptococose, sendo esta a principal causa micológica de morbidade e mortalidade.

A associação dessa enfermidade com a AIDS apresenta uma taxa de letalidade bastante elevada, variando de $33 \%$ a 62,5\%. Mas, com a introdução da terapia antirretroviral e esquemas profiláticos com antifúngicos, ocorreu uma redução dessa infecção em portadores de HIV. Esta infecção também acomete pacientes HIV negativos, como por exemplo, transplantados, portadores de doenças autoimunes e portadores de malignidades, sendo que nesses casos a taxa de letalidade varia de $24,2 \%$ a $42 \%$ (PASA, 2011). 
Segundo (BECK, 2003),

Histoplasmose e uma doença em que o agente causador é o fungo, Histoplasma capsulatum, eminentemente intracelular em fase parasitária, que se reproduz nos macrófagos. Esta infecção micótica, clinicamente, pode se manifestar sob formas assintomáticas, benignas (simulando resfriado comum), moderadamente graves ou graves. Neste último caso as lesões assumem o aspecto de uma pneumonite aguda com hepatesplenomegalia, febre, tosse, dispnéia e emagrecimento, ou um tipo progressivo crônico, com lesões pulmonares escavadas. A hiperplasia dos macrófagos no baço e no fígado é a causa principal da espleno e hepatomegalia, quase constantes. A contaminação se dá pela inalação dos fungos contidos nas fezes dos pombos.

As dermatites são comuns atingir pessoas que tem contato mais próximo aos pombos, sendo causadas muitas vezes pelos ectoparasitas presentes nos mesmos (BECK, 2003).

Este estudo teve como objetivo observar a presença de pombos e o comportamento dos mesmos perante a dinâmica da praça Cônego Ângelo Tardio Bruno, no município de Ituiutaba, MG. Analisar os hábitos diários das pessoas que frequentam, e os eventos que ocorrem na praça e em seu entorno, quanto a procedimentos que possam atrair estes animais e se são aplicadas medidas de controle para pombos, enfatizando o risco de infecção humana causada pela presença destes animais em locais públicos.

\section{MATERIAIS E MÉTODOS}

O trabalho foi desenvolvido na Praça Cônego Ângelo Tardio Bruno, situada na região central do município de Ituiutaba/MG, que possui uma área total de 12.616,00 $m^{2}$.

O levantamento da presença de pombos Columbiformes e a análise da dinâmica da praça, quanto a procedimentos que possam atrair estes animais e se são aplicadas medidas de controle para pombos foi realizado por meio de observações diretas dentro da referida praça. As atividades de observação tiveram início no dia 05 até 13 fevereiro de 2016, totalizando 09 dias de observação. As observações foram realizadas pela manhã, compreendendo o período das 07:00 às 11:00h e a tarde das 13:00 às 17:30h. Cada visita teve duração média de quatro horas, sendo que o período das visitas está relacionado com o período de maior atividade das aves que é o alvorecer, e devido à maior movimentação de pessoas no comércio de alimentação 
Observação sobre a presença de Columba livia doméstica em uma praça no município de Ituiutaba-MG

existente na praça. Para as observações das espécies foram realizados registros fotográficos e observações visuais. Para o entorno da praça foi feito apenas observações visuais, por se tratar da maioria de propriedades privadas. As observações foram realizadas com o auxílio de câmera fotográfica SONY 14.1 MEGA PIXELS com 4X Zoom Óptico.

\section{RESULTADOS E DISCUSSÃO}

Como esperado, foi constato a presença dos pombos tanto no período da manhã, como também à tarde. Em paralelo, no local, foi verificado a presença de outras espécies, como pardais e araras.

No trabalho de campo foi observado que no período da manhã, os pombos ficam na praça se alimentando dos restos de alimentos deixados ali da noite anterior (Figura 1) devido ao comércio de alimentos que ali existente no período da noite, a população mudou os hábitos alimentares, passando a se alimentar mais nas ruas onde há um grande fluxo dessas aves como no caso desse estudo. No decorrer do dia, isto volta a acontecer, pois é quando o comércio de alimentos que atua durante o dia começa a funcionar e tem maior movimentação de pessoas, com isto a uma grande quantidade de resíduos alimentares presente na praça e em seu entorno.

Segundo França et al., (2013) na contemporaneidade, a alimentação é caracterizada pelo estilo de vida moderno, marcada pela escassez de tempo para preparo e consumo de alimentos, o que leva à emergência de alimentos do tipo fast food.

Foi verificado in loco o hábito de jogar alimentos como o arroz e milho cozido, pela própria população com a intenção de alimentar os pombos e cães que ali ficam.

Na praça ocorre a limpeza pela manhã (Figuras 1 e 2), através da varredura, onde há um grande risco de contaminação dos zeladores que cuidam da limpeza do local e das pessoas que por ali passam ou estão trabalhando neste momento, pois, em dias secos, o pó aspirado dessas fezes secas quando varridas pode trazer grandes riscos para a saúde.

Observa-se, então, que para evitar contaminação pelas fezes, se faz necessário antes de varrer, umedecê-las com desinfetante e utilizar máscara e luvas ao fazer a limpeza do local, o que não é realizado pela zeladoria da praça. 
Outro ponto levantado foi o de que os pombos Columba livia doméstica ficam alojados nas frestas do prédio da Prefeitura (Figura 3) na igreja e no fórum, eles usam estes lugares como ponto de observação de sua vizinhança e das fontes de alimento.

De acordo com Nunes (2003), os pombos urbanos se adaptaram a este tipo de ambiente devido à oferta abundante de abrigo, ausência de predadores e a grande quantidade alimentos disponíveis.

Foi constatado que na praça, em estudo, tem um Projeto para alimentar cães (Cão de Rua) conforme mostrado na Figura 4, onde ficam vasilhas de água e ração para cães de rua. Esta é uma iniciativa positiva, uma vez que nas ruas da cidade encontramos muitos cães abandonados, porém o problema é que o alimento e a água atraem os pombos, aonde eles vão para se alimentar, trazendo como consequência o depósito de fezes contaminadas por patógenos na água dos cães e, por conseguinte, podendo trazer doenças para os mesmos. Segundo Larrson, et al., (2003), "o primeiro caso de criptococose canina aqui no Brasil, foi ocasionado pelo contato com os dejetos de pombos Columba livia doméstica".

Figura 1: Pombos na Praça Cônego Ângelo Tardio Bruno.

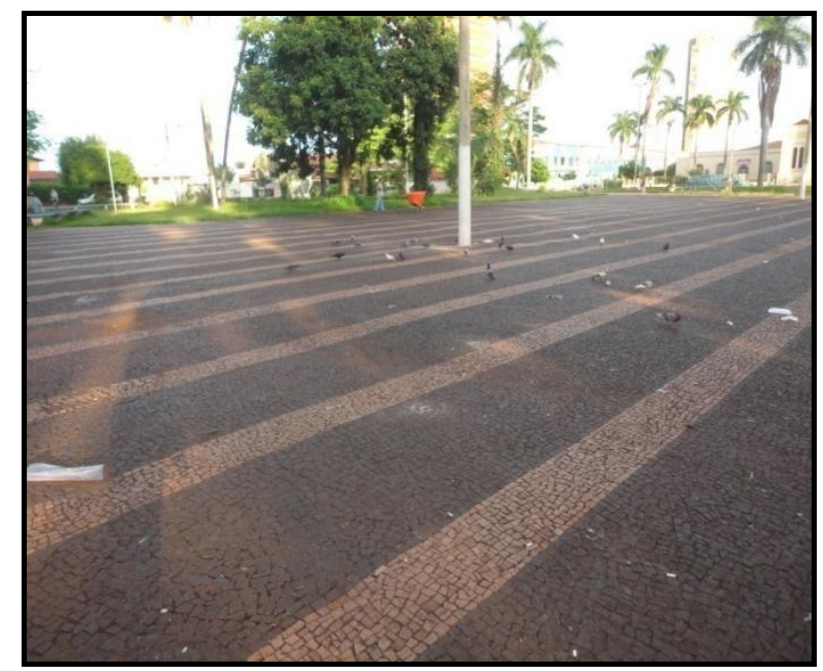

Fonte: Crédito do autor. 
Observação sobre a presença de Columba livia doméstica em uma praça no município de Ituiutaba-MG

Figura 2: Fezes dos pombos na praça Cônego Ângelo Tardio Bruno.

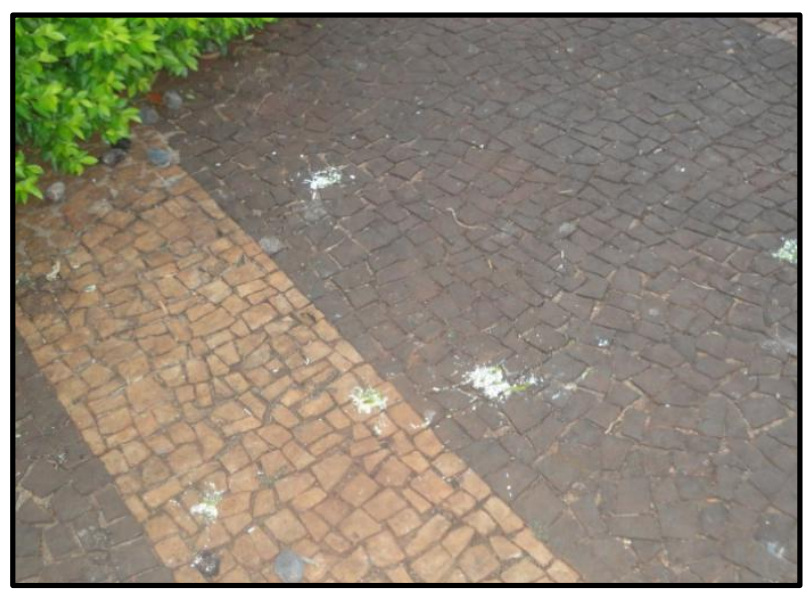

Fonte: Crédito do autor.

Figura 3: Pombos no prédio da Prefeitura de Ituiutaba na Praça Cônego Ângelo Tardio Bruno.

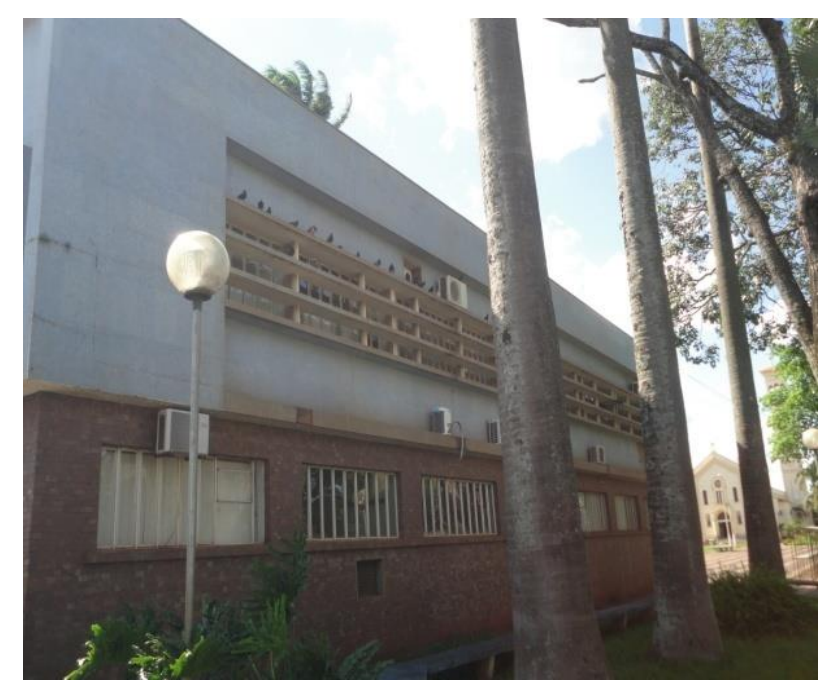

Fonte: Crédito do autor.

Figura 4: Projeto Cão de Rua na Praça Cônego Ângelo Tardio Bruno.

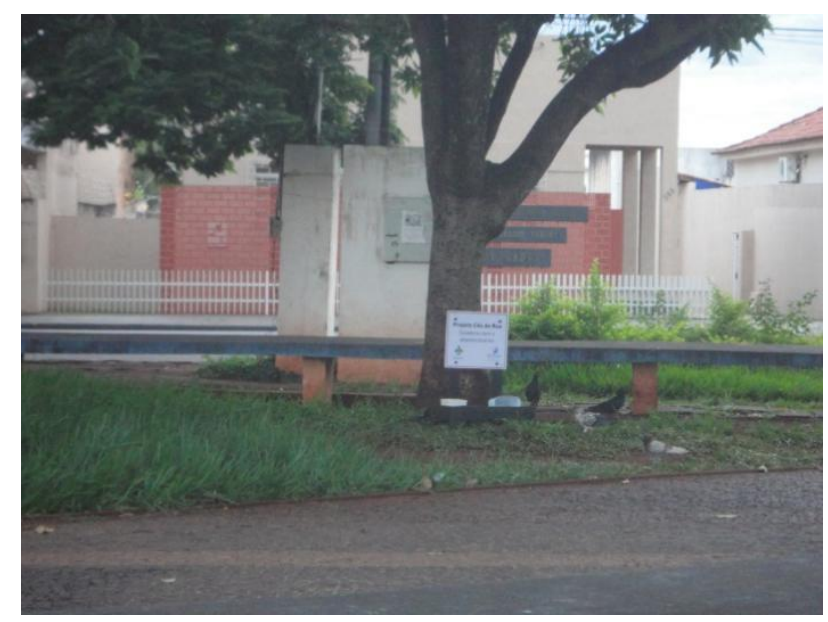

Fonte: Crédito do autor. 
Além de todos os problemas citados, próximo à praça fica localizado um hospital de média complexidade e que atende apenas a rede particular, onde pode ocorrer a presença de ninhos nos telhados do hospital, podendo trazer riscos à saúde dos pacientes e funcionários. Por se tratar de uma propriedade particular este prédio e vários outros ao entorno da praça não foi realizado o levantamento da presença destes pombos.

As pesquisas envolvendo o risco que as fezes de pombos trazem tanto para o homem como para os animais devem ser incrementadas, uma vez que se é falado pouco, principalmente aqui no município de Ituiutaba. Deve ser criado um programa de conscientização da população quanto aos riscos da contaminação pelas fezes e a importância de não alimentar os pombos.

De acordo com Noronha, (2010) a superpopulação dos pombos causa uma vida estressante entre eles, diminuindo a qualidade de vida dessas aves, pois eles passam a competir por alimentos, por poleiros, ocorrem traumatismos e transmissão de doenças entre eles.

Vale ressaltar que existem no mercado técnicas e produtos apropriados para se promover o controle e o manejo dos pombos, o que poderia evitar a disseminação de doenças causadas por estes vetores. Colocar telhas específicas contra a presença dos pássaros em telhados; utilizar telas de proteção em janelas, varandas e caixas de ar-condicionado; uso de repelentes em telhados, beirais e outros para afastá-los entre outros.

De acordo com Nunes (2003), para que seja implantado ações de controle populacional é necessário que haja vistorias zoosanitárias ao local, identificando todos os locais onde tem o problema, e em torno do foco onde ficam os pombos para que seja definido medidas mais adequadas. Em relação a isto, segundo informações do Centro de Controle de Zoonoses de Ituiutaba, não foi feito até o momento o levantamento das doenças que os pombos transmitem, e nem o controle destes vetores, mas eles têm a consciência dos riscos que podem trazer para a saúde humana. 
Observação sobre a presença de Columba livia doméstica em uma praça no município de Ituiutaba-MG

\section{CONCLUSÕES}

Através dos resultados obtidos, conclui-se que há uma grande quantidade de pombos que se alimentam de restos de alimentos jogados pela população diretamente no chão da praça de Ituiutaba, e nos cestos de lixo. Medidas de controle populacional de pombos devem ser implementadas. Uma forma de controle é não alimentar essas aves para que elas tenham a população controlada e possam exercer o seu papel na natureza, pois a ausência de predadores naturais favorece o aumento das aves, e com isto evitar doenças provocadas por estes vetores aos animais e o homem.

Ituiutaba necessita de uma atenção maior com relação a esta espécie invasora a Columba livia doméstica, pois, esta ave pode se tornar um problema de saúde pública. Para o controle ser eficiente deve existir uma parceria com a Prefeitura, Secretaria do Meio Ambiente e Centro de Controle de Zoonoses, com a criação de resoluções no município, proibindo alimentar os pombos, com aplicação de multas, utilizando placas nas praças ou em qualquer lugar público, e com trabalho educativo em todos os meios de comunicação, e o fornecimento de cartilhas para os alunos nas escolas, informando das doenças que as fezes dessas aves podem transmitir e que é proibido exterminar estas aves.

Observa-se que durante a realização deste trabalho não foi visualizado nenhuma política pública específica para o controle destes vetores na praça avaliada. Por se tratar de uma área com uma grande quantidade de imóveis, outros trabalhos devem ser realizados para levantar a presença destes animais nos demais prédios, e para criar alternativas de alimentação segura dos caninos que vivem próximos a este local e que são alimentados pelo projeto Cão de Rua. Como o problema já está instalado na praça, se faz necessário através de uma equipe multidisciplinar verificar se os pombos ali presentes estão contaminados com algumas doenças que posem ser consideradas zoonoses.

\section{REFERÊNCIAS}

BECK, P. V. Estudo das infestações de pombos nas edificações da cidade de Brasília.17f. Monografia em Biologia. Centro Universitário de Brasília, 2003. 
Observação sobre a presença de Columba livia doméstica em uma praça no município de Ituiutaba-MG

FRANÇA, F. C. O.; MENDES, A. C. R.; ANDRADE, I. S.; RIBEIRO, G. S.; PINHEIRO, I. B. Mudanças dos hábitos alimentares provocados pela industrialização e o impacto sobre a saúde do brasileiro. In: Seminário de Alimentação e Cultura, Bahia. ANAIS... Bahia: Centro de Estudos do Recôncavo Baiano- Bahia, 2013.

LARSSON, C. E.; OTSUKA, M.; MICHALANY, N. S.; BARROS, P. S. M.; GAMBALE, W.; SAFATLE, A. M. V. Criptococose canina: relato de caso. Revista Arquivo Brasileiro de Medicina Veterinária e Zootecnia, vol.55 n. 5 Belo Horizonte, 2003.

NORONHA, M. L. M. de. Pombos urbanos: biologia, problemas, manejo e controle. Disponível $<$ http://crmvrj.org.br/forum\%20de\%20saude\%20publica/controle\%20de\%20p

ombos\%20urbanos.pdf>. Acesso em: 22 de dez. de 2016.

NUNES, V. de F. P. Pombos Urbanos: O desafio de controle. Revista Biológica, São Paulo, n.1-2, p. 89-92, jan/dez/2003.

PASA, C. R. Tipagem molecular e suscetibilidade antifúngica de Cryptococcus isolados de pacientes em Hospital Universitário com investigação domiciliar. Dissertação (Programa de Pós-Graduação em Saúde e Desenvolvimento). Universidade Federal de Mato Grosso do Sul, Campo Grande, 2011.

PINTO, L. I. S. A criptococose meníngea em doentes com infecção HIV. Faculdade de Medicina do Porto. Revista Arquivos de Medicina, 2010.

PREFEITURA DO MUNICÍPIO DE SÃO PAULO. Manejo dos pombos urbanos. Cartilha. Disponível em: <http://www.prefeitura.sp.gov.br/cidade/secretarias/upload/PombosUrbanos_1

253821868.pdf>. Acesso em: 26 de set. de 2016

SILVA, J. O.; CAPUANO, D. M. Ocorrência de Cryptococcus spp. e de parasitas de interesse em saúde pública, nas excretas de pombos na cidade de Ribeirão Preto, São Paulo, Brasil. Revista do Instituto Adolfo Lutz. São Paulo, V. 67, n. 2, 2008.

STIPP, M. E. F.; SILVA, M. A.; BERTACHI, M. H. Caracterização de impactos ambientais visuais causados por cemitérios em cidades de grande porte. Estudo de caso do cemitério São Pedro na cidade de Londrina-PR. Revista Geografia e Pesquisa, Ourinhos, v. 5, n. 2, ano 2011. 